\title{
Hyponatremia and SIADH Frequency in Clinically Euvolemic Patients Receiving Chemotherapy: Prospective Study in Unselected Patients' Cohort
}

\section{Dada Reyad ${ }^{1,2 *}$, Jamal Zekri ${ }^{1,2}$, Kamel Farag ${ }^{1,3}$ and Mohamed Bayoumy ${ }^{1}$}

${ }^{1}$ Department of Oncology, King Faisal Specialist Hospital and Research Center, Jeddah, Saudi Arabia

${ }^{2}$ College of Medicine, Al-Faisal University, Riyadh, Kingdom of Saudi Arabia

${ }^{3}$ Department of Oncology, Mansoura University, Mansoura, Egypt

\begin{abstract}
Purpose: Biochemical hyponatremia is a common electrolyte abnormality in patients with cancer. In this prospective single center trial we aim to study the frequency of hyponatremia in patients receiving chemotherapy with special emphasis on syndrome of inappropriate secretion of anti-diuretic hormone (SIADH).

Patients and Methods: This is a prospective study of consecutive patients receiving different types of outpatient chemotherapy between January 2013 and June 2014. Serum Sodium was measured as part of routine assessment for all patients receiving chemotherapy. Euvolemic patients with hyponatremia $(\mathrm{Na}<135 \mathrm{mmol} / \mathrm{L}$ ) were also tested for Serum and urine osmolality and urinary Na excretion. Criteria of SIADH are: serum Osmolality $<275 \mathrm{mOsmol} /$ $\mathrm{kg}$, urine Osmolality $>100 \mathrm{mOsmol} / \mathrm{kg}$ and urinary Sodium $>30 \mathrm{mmol} / \mathrm{L}$.

Results: 1254 patients received different chemotherapy regimens were screened and 1150 fulfilled the inclusion criteria. Median age was 55 year (19-75). Biochemical hyponatremia developed in 105 (9.1\%) of all patients and in $42 / 298(14 \%), 25 / 357(7 \%)$ and $38 / 495(7.7 \%)$ of patients who received cisplatin, carboplatin/oxaliplatin and non-platinum chemotherapy regimens respectively. 68/105 (65\%) fulfilled biochemical criteria of SIADH of which $26 / 42(62 \%), 13 / 25(52 \%)$ and $29 / 38(76 \%)$ of hyponatremic patients received cisplatin, carboplatin/oxaliplatin and non-platinum regimens respectively. Cisplatin based regimens were significantly associated with SIADH compared to non-cisplatin regimens (OR: 1.521, 95\% Cl: 1.105-2.093; $p=0.022$ ).
\end{abstract}

Conclusion: $9.1 \%$ of euvolemic patients receiving out-patient chemotherapy manifest a degree of biochemical hyponatremia with highest risk associated with cisplatin based regimens. Hyponatremia can be attributed to SIADH in two thirds of cases.

Keywords: Hyponatremia; SIADH; Renal salt-wasting syndrome; Chemotherapy

\section{Introduction}

Hyponatremia (defined as a serum sodium concentration $<135$ $\mathrm{mmol} / \mathrm{L}$ ) is the most frequently encountered electrolyte disturbance in clinical practice [1]. It can present with nausea, vomiting and generalized weakness. Severe hyponatremia (sodium $<125 \mathrm{mmol} / \mathrm{l}$ ), particularly if develops rapidly (within 48 hours) may lead to confusion, hallucinations, seizures, coma, and respiratory arrest [2]. Severe hyponatremia is reported to be associated with significant morbidity and increased mortality (up to 60 folds) compared with normo-natremic controls [3-6].

There are three main pathophysiological forms of hyponatremia [7]. (a) Hypovolemic hyponatremia caused by intravascular volume depletion and is treated by volume replacement. (b) Hypervolemic hyponatremia caused by dilutional effect of fluid overload which is treated by diuresis. (c) Euvolemic hyponatremia caused by excessive sodium excretion. SIADH is an example of the latter. Recently, a new class of drugs, vasopressin V2-receptor antagonists (vaptans), showed promising efficacy in SIADH patients [8,9].

Hyponatremia is a common electrolyte abnormality in patients with cancer. Causes of hyponatremia in this specific population include chemotherapy, decreased fluid intake, diuretics, intravascular volume changes, renal salt-wasting syndrome and syndrome of inappropriate secretion of antidiuretic hormone (SIADH). The most frequently reported chemotherapeutic drugs causing hyponatremia are cisplatin, vincristine, vinblastine, and cyclophosphamide [10]. The pathophysiology of hyponatremia induced by these drugs is only partly known. Renal salt wasting is described with cisplatin and carboplatin [11]. The syndrome of inappropriate antidiuretic hormone secretion was reported secondary to vinca alkaloids and cisplatin and other agents [11].

Early recognition of hyponatremia enables prompt intervention leading to less complications, shorter hospitalization time and improvement of outcome. We studied the frequency of hyponatremia in patients receiving systemic chemotherapy at our hospital with special emphasis on SIADH.

*Corresponding author: Reyad D, Depart Department of Oncology MBC J-64 King Faisal Specialist Hospital and Research Center, P.O. Box 40047, Jeddah 21499, Saudi Arabia, Tel: 966-2-6677777 ext. 64065; Fax: 966-2-6677777 ext 64030; E-mail: rdada@kfshrc.edu.sa

Received January 06, 2016; Accepted March 11, 2016; Published March 14 2016

Citation: Reyad D, Zekri J, Farag K, Bayoumy M (2016) Hyponatremia and SIADH Frequency in Clinically Euvolemic Patients Receiving Chemotherapy: Prospective Study in Unselected Patients' Cohort. J Cancer Sci Ther 8: 055-058. doi:10.4172/1948-5956.1000390

Copyright: $\odot 2016$ Reyad D, et al. This is an open-access article distributed unde the terms of the Creative Commons Attribution License, which permits unrestricted use, distribution, and reproduction in any medium, provided the original author and source are credited. 


\section{Patients and Methods}

This is a prospective study of all patients attending for administration of different types of out-patient chemotherapy between January 2013 and June 2014. All patients $\geq 18$ year and receiving chemotherapy in metastatic or curative setting for malignant disease were screened. Measurement of serum electrolytes (including sodium) was part of routine assessment prior to administration of each chemotherapy cycle. Only those patients who developed hyponatremia after chemotherapy were further investigated by measuring urine sodium $(\mathrm{mmol} / \mathrm{l})$, serum osmolality $(\mathrm{mOsmol} / \mathrm{kg})$ and urine osmolality $(\mathrm{mOsmol} / \mathrm{kg})$. Patients with hyponatremia and clinical sings of dehydration (history of poor fluid intake, recent diarrhea and vomiting) prior to start of chemotherapy were excluded. Patients on diuretics or psychotropic drugs and those with abnormal cortisol, TSH and fT4 levels were also excluded. Hyponatremia was classified as mild, moderate and severe according to the European Society of Intensive Care Medicine (ESICM), the European Society of Endocrinology (ESE) and the European Renal Association - European Dialysis and Transplant Association (ERAEDTA), represented by European Renal Best Practice (ERBP) [12] (Table 1). SIADH was diagnosed according to criteria for diagnosis of SIADH developed by Thompson, et al. [6] (Table 2). The study was designed to evaluate the rate of hyponatremia and SIADH among unselected patients receiving different chemotherapy regimens with palliative or curative intent in daily practice.

The intention of this study is to represent the heterogeneity of tumor types treated by various chemotherapy regimens in routine daily practice. Due to diversity of administered chemotherapy protocols, they were identified into 3 broad categories (a) cisplatin, (b) carboplatin or oxaliplatin and (c) non-platinum based regimens. The association between SIADH and relevant factors was tested. These factors include gender, age, chemotherapy regimen (cisplatin and others), cycles of chemotherapy, hemoglobin, creatinine, uric acid and urea. Two sided Chi-square test was applied for univariate analysis and binary logistic regression test has been used for multivariate analysis using SPSS version 20 . The study was approved by the ethical committee.

\section{Results}

$104 / 1254(8.3 \%)$ patients receiving narcotics or diuretics were excluded. Patients' characteristics are listed in Table 3. The median age of our patient population was 55 years. Gastrointestinal tract primary $34 / 105$ (32\%) was the commonest diagnosis followed by breast cancer (21\%) and 74/105 (70.5\%) of patients were receiving chemotherapy in the first line setting. 1150 patients fulfilled the inclusion criteria.

\begin{tabular}{|l|l|}
\hline Mild hyponatremia & $\begin{array}{l}\text { Biochemical finding of a serum sodium } \\
\text { concentration between } 130 \text { and } 135 \mathrm{mmol} / \mathrm{l}\end{array}$ \\
\hline Moderate hyponatremia & $\begin{array}{l}\text { Biochemical finding of a serum sodium } \\
\text { concentration between } 125 \text { and } 129 \mathrm{mmol} / \mathrm{l}\end{array}$ \\
\hline Severe hyponatremia & $\begin{array}{l}\text { Biochemical finding of a serum sodium } \\
\text { concentration }<125 \mathrm{mmol} / \mathrm{l}\end{array}$ \\
\hline
\end{tabular}

Table 1: Definition of hyponatremia based on biochemical severity [12].

Plasma sodium $<135 \mathrm{mmol} / \mathrm{l}$

Urine osmolality $>100 \mathrm{mOsm} / \mathrm{kg}$

Urine sodium $>30 \mathrm{mmol} / \mathrm{l}$

Patient clinically euvolaemic

Exclusion of glucocorticoid deficiency

Hyponatraemia

Normal salt intake

Table 2: Essential criteria for the diagnosis of SIADH [6].
298 (26\%), $357(31 \%)$ and 495 (43\%) patients received cisplatin, carboplatin/oxaliplatin and non-platinum based chemotherapy regimens respectively. 105/1150 (9.1\%) patients had hyponatremia and are the subject of subsequent analysis. (Table 3)

Hyponatremia was mild, moderate and severe in 3.4\%, 5.7\% and $0.09 \%$ respectively. Table 4 illustrates the frequency and degree of hyponatremia among patients receiving different chemotherapy regimens. Overall 68/105 (65\%) fulfilled biochemical criteria of SIADH. 26/42 (62\%), 13/25 (52\%) and 29/38 (76\%) of patients receiving cisplatin, other platinum and non-platinum based regimens respectively fulfilled biochemical criteria of SIADH. In univariate analysis cisplatin based regimens were significantly associated with SIADH compared to non-cisplatin regimens (OR: 1.521, 95\% CI: 1.105-2.093; $\mathrm{p}=0.022$ ) and other platinum regimens (OR: 1.51, 95\% CI: 1.189-1.917; $\mathrm{p}=0.008$ ). However, the statistical significance was lost on multivariate analysis. Additionally, there was no association between SIADH and gender (male vs. female; $p=0.22$ ), age ( $<60$ vs $\geq 60$ years; $\mathrm{p}=0.836$ ), number of chemotherapy cycles ( $1-2$ vs $>2$ cycles; $\mathrm{p}=1.0$ ), hemoglobin, creatinine, uric acid and urea.

\section{Discussion}

The frequency of hyponatremia in cancer patients receiving chemotherapy is not well documented in the literature. To study chemotherapy associated hyponatremia, we screened a large unselected cohort $(n=1254)$ of patients with cancer receiving different chemotherapy regimens. Subsequently, we excluded those with clinical hypovolemia and those receiving non-chemotherapy drugs that may cause hyponatremia [13-15]. We found that $9.1 \%$ of these patients manifest hyponatremia which was mostly of mild to moderate severity. 26\% (298/1150) of screened patients received cisplatin based regimens. Platinum compounds, in particular cisplatin are recognized to induce sodium loss through renal tubular toxicity [11]. Grade 3/4 hyponatremia was reported in $15 \%$ and $30.7 \%$ of 79 patients receiving brand and generic cisplatin respectively [16]. In our larger cisplatin treated cohort $(\mathrm{n}=298)$, all degree hyponatremia and moderate to severe hyponatremia was observed in $14.1 \%$ and $10 \%$ of patients respectively. In line with previous reports, hyponatremia was also associated with other platinum (7\%) and non-platinum (7.7\%) agents albeit less frequently than with cisplatin [11].

Several case reports about salt wasting and SIADH in patients receiving chemotherapy were published [17-19]. Examples for drugs that were reported to cause SIADH include platinum, vincristine

\begin{tabular}{|l|c|}
\hline Patient Demographics & $\mathbf{n = 1 0 5}$ \\
\hline Gender & $59(56 \%)$ \\
\hline Female & $46(44 \%)$ \\
\hline Median age & $55(19-75)$ years \\
\hline Primary tumor & \\
\hline Gastrointestinal & $34(32 \%)$ \\
\hline Breast & $22(21 \%)$ \\
\hline Gynecological & $13(12 \%)$ \\
\hline Lymphomas & $11(10.5 \%)$ \\
\hline Lung & $10(9.5 \%)$ \\
\hline Urological & $9(8.5 \%)$ \\
\hline Others & $6(5.5 \%)$ \\
\hline Line of chemotherapy & $74(70.5 \%)$ \\
\hline First line & $31(29.5 \%)$ \\
\hline Subsequent & \\
\hline
\end{tabular}

Table 3: Patients' characteristics. 


\begin{tabular}{|c|c|c|c|c|}
\hline & $\begin{array}{c}\text { Cisplatin based } \\
\text { chemotherapy }(n=298)\end{array}$ & $\begin{array}{l}\text { Carboplatin or oxaliplatin based } \\
\text { chemotherapy }(n=357)\end{array}$ & $\begin{array}{l}\text { Non-platinum based } \\
\text { chemotherapy }(n=495)\end{array}$ & Total $(n=1150)$ \\
\hline Hyponatremia & $42(14.1 \%)$ & $25(7 \%)$ & $38(7.7 \%)$ & $105(9.1 \%)$ \\
\hline SIADH & $26(8.7 \%)$ & $13(3.6 \%)$ & $29(5.9 \%)$ & $68(5.9 \%)$ \\
\hline Mean serum $\mathrm{Na}(\mathrm{mmol} / \mathrm{L})$ & 128.9 & 129.1 & 129.5 & 129.2 \\
\hline Range & $(123-133)$ & $(126-133)$ & $(127-133)$ & $(123-133)$ \\
\hline \multicolumn{5}{|c|}{ Grade of hyponatremia } \\
\hline Mild (130-135) & $12(4 \%)$ & $8(2.2 \%)$ & $19(3.8 \%)$ & $39(3.4 \%)$ \\
\hline Moderate $(125-130)$ & $29(9.7 \%)$ & $17(4.8 \%)$ & $19(3.8 \%)$ & $65(5.7 \%)$ \\
\hline Severe $(<125)$ & $1(0.3 \%)$ & None & None & $1(0.09 \%)$ \\
\hline Hyponatremia fulfilling SIADH & $26 / 42(62 \%)$ & $13 / 25(52 \%)$ & $29 / 38(76 \%)$ & $68 / 105(65 \%)$ \\
\hline
\end{tabular}

Table 4: Details of hyponatremia among patients receiving different chemotherapy regimens.

\begin{tabular}{|l|c|c|}
\hline Factor & Odds ratio- 95\% Cl \\
\hline Gender & $1.55(0.64-3.71)$ & P-value \\
\hline Age (median: 55 years) & $1.02(0.98-1.05)$ & 0.32 \\
\hline Chemotherapy Regimen (Cisplatin vs. others) & $0.87(0.36-2.06)$ \\
\hline Chemotherapy cycles (1-2 vs. >2 cycles) & $0.84(0.34-2.05)$ & 0.75 \\
\hline Hemoglobin & $1(0.98-1.03)$ & 0.70 \\
\hline Serum Creatinine & $0.98(0.95-1.01)$ & $1(0.99-1)$ \\
\hline Uric Acid & 0.62 & 0.29 \\
\hline Urea & $0.97(0.84-1.11)$ \\
\hline
\end{tabular}

Table 5: Multivariate Analysis.

[20,21], cyclophosphamide [17], vinorelbine [22-25], docetaxel [26]. In the majority of those cases platinum was the main reason for hyponatremia [16,18,19,27-30]. New targeted therapies like imatinib [31], alemtuzumab [32] have been reported to cause SIADH also.

Our study is the first in the literature investigating the frequency of SIADH in unselected patients' cohort regardless of the type of antineoplastic agents or the cancer type. We rigorously attempted to exclude patients with other causes of hyponatremia as those with dehydration and those receiving diuretics and/or psychotropic drugs which are known to cause disturbance of the sodium balance [13$15,33]$.

In our results and considering all patients, SIADH was more frequent with cisplatin $26 / 298(8.7 \%)$ than other platinum regimens $13 / 357$ (3.6\%). Around two thirds 68/105 (65\%) of patients with hyponatremia fulfilled the criteria of SIADH. Hyponatremia and SIADH were more frequently associated with cisplatin than other platinum regimens (Table 4). These findings were supported by the results of univariate analysis which showed cisplatin based regimens were statistically significantly associated with SIADH compared to non-cisplatin and other platinum regimens. However, this statistical significance was lost in multivariate analysis which included other potential factors that could influence SIADH (Table 5). This could be explained by the extensively heterogeneous tumor sites and chemotherapy protocols also. Feature studies should focus on groups of patients with particular tumor sites and receiving specific chemotherapy regimen. Literature on carboplatin and oxaliplatin associated hyponatremia and SIADH are scarce and are limited to case reports and very small patients' series [34,35]. Grade III hyponatremia was observed in phase II study of oxaliplatin in patients with unresectable, metastatic or recurrent hepatocellular cancer $(n=15)$ [36]. Our findings indicate that carboplatin and oxaliplatin associated hyponatremia and SIADH are commoner than expected.

The broad heterogeneity of tumor sites and chemotherapy regimens (24 regimes) used in our patients cohort practically preclude analysis of each individual tumor site and chemotherapy regimen.

Hyponatremia is associated with poor prognosis and has a negative impact on quality of life [37-40]. Our relatively large study sheds light on the scale and magnitude of frequency of hyponatremia in patients receiving systemic chemotherapy. However, the heterogeneity of patients, broad cancer sites, chemotherapy regimens (24 regimens), stages of disease and lines of treatment practically precludes any meaningful survival analysis or analysis of each individual tumor site and chemotherapy regimen separately. Relevant blood and urine tests were carried out on the date of each chemotherapy cycle. We did not routinely perform tests between cycles, which may limit our end results and can underestimate the real frequency of hyponatremia in our patients.

\section{Conclusion}

To our knowledge this is the first published prospective study analyzing frequency and grade of hyponatremia and SIADH in unselected euvolemic patients' population receiving chemotherapy. About $9 \%$ of these patients manifest a degree of hyponatremia which fulfills the biochemical criteria of SIADH in $65 \%$ of these patients. Cisplatin poses higher risk of hyponatremia and SIADH than other platinum and non-platinum regimens. Chemotherapy induced hyponatremia is frequently observed and is commonly attributed to SIADH. Treating oncologists should be aware of this complication particularly in patient undergoing cisplatin based therapy.

\section{Author contributions}

Dada, Zekri, Farag and Bayoumy contributed on the design, patients' selection, data collection and processing and manuscript writing.

\section{Acknowledgements}

We thank our patients for participation on this study.

\section{References}

1. Thompson C, Hoorn EJ (2012) Hyponatraemia: an overview of frequency clinical presentation and complications. Best Pract Res Clin Endocrinol Metab 26: S1-S6.

2. Ellison DH, Berl T (2007) Clinical practice. The syndrome of inappropriate antidiuresis. N Engl J Med 356: 2064-2072.

3. Gill G, Huda B, Boyd A, Skagen K, Wile D, et al. (2006) Characteristics and 
Citation: Reyad D, Zekri J, Farag K, Bayoumy M (2016) Hyponatremia and SIADH Frequency in Clinically Euvolemic Patients Receiving Chemotherapy: Prospective Study in Unselected Patients' Cohort. J Cancer Sci Ther 8: 055-058. doi:10.4172/1948-5956.1000390

mortality of severe hyponatraemia: a hospital-based study. Clin Endocrinol (Oxf) 65: 246-249.

4. Basu A, Ryder RE (2014) The syndrome of inappropriate antidiuresis is associated with excess long-term mortality: a retrospective cohort analyses. J Clin Pathol 67: 802-806.

5. Miyashita J, Shimada T, Hunter AJ, Kamiya T (2012) Impact of hyponatremia and the syndrome of inappropriate antidiuresis on mortality in elderly patients with aspiration pneumonia. J Hosp Med 7: 464-469.

6. Thompson CJ, Crowley RK (2009) Hyponatraemia. J R Coll Physicians Edinb 39: 154-157.

7. Sterns RH (2015) Disorders of plasma sodium--causes, consequences, and correction. N Engl J Med 372: 55-65.

8. Bordi P, Tiseo M, Buti S, Regolisti G, Ardizzoni A (2015) Efficacy and safety of long-term tolvaptan treatment in a patient with SCLC and SIADH. Tumori 101: e51-53.

9. Chen S, Zhao JJ, Tong NW, Guo XH, Qu MC, et al. (2014) Randomized double blinded, placebo-controlled trial to evaluate the efficacy and safety of tolvaptan in Chinese patients with hyponatremia caused by SIADH. J Clin Pharmacol 54: 1362-1367.

10. Liamis G, Milionis $\mathrm{H}$, Elisaf $M$ (2008) A review of drug-induced hyponatremia Am J Kidney Dis 52: 144-153.

11. Berghmans T (1996) Hyponatremia related to medical anticancer treatment. Support Care Cancer 4: 341-350.

12. Spasovski G, Vanholder R, Allolio B, Annane D, Ball S, et al. (2014) Clinica practice guideline on diagnosis and treatment of hyponatraemia. Eur $\mathrm{J}$ Endocrinol 170: G1-G47.

13. Arinzon ZH, Lehman YA, Fidelman ZG, Krasnyansky II (2002) Delayed recurrent SIADH associated with SSRIs. Ann Pharmacother 36: 1175-1177.

14. Bavbek N, Kargili A, Akcay A, Kaya A (2006) Recurrent hyponatremia associated with citalopram and mirtazapine. Am J Kidney Dis 48: e61-62.

15. Martínez-Cortés M, Ogando-Portilla N, Pecino-Esquerdo B, Pérez-Maciá V (2013) Antidepressant induced recurrent hyponatremia: A case report. Actas Esp Psiquiatr 41: 361-364.

16. Ochi N, Yamane H, Hotta K, Fujii H, Isozaki H, et al. (2014) Cisplatin-induced hyponatremia in malignancy: comparison between brand-name and generic formulation. Drug Des Devel Ther 8: 2401-2408.

17. Elazzazy S, Mohamed AE, Gulied A (2014) Cyclophosphamide-induced symptomatic hyponatremia, a rare but severe side effect: a case report. Onco Targets Ther 7: 1641-1645.

18. Gota V, Kavathiya K, Doshi K, Gurjar M, Damodaran SE, et al. (2014) High plasma exposure to pemetrexed leads to severe hyponatremia in patients with advanced non-small cell lung cancer receiving pemetrexed-platinum double chemotherapy. Cancer Manag Res 6: 261-265.

19. lyer AV, Krasnow SH, Dufour DR, Arcenas AS (2003) Sodium-wasting nephropathy caused by cisplatin in a patient with small-cell lung cancer. Clin Lung Cancer 5: 187-189.

20. Hammond IW, Ferguson JA, Kwong K, Muniz E, Delisle F (2002) Hyponatremia and syndrome of inappropriate anti-diuretic hormone reported with the use of Vincristine: an over-representation of Asians?. Pharmacoepidemiol Drug Sa 11: $229-234$

21. Escuro RS, Adelstein DJ, Carter SG (1992) Syndrome of inappropriate secretion of antidiuretic hormone after infusional vincristine. Cleve Clin J Med 59: 643-644.

22. Garrett CA, Simpson TA Jr (1998) Syndrome of inappropriate antidiuretic hormone associated with vinorelbine therapy. Ann Pharmacother 32: 13061309.

23. Hoang M, Varughese J, Ratner E (2013) Syndrome of Inappropriate Antidiuretic Hormone after vinorelbine treatment. J Oncol Pharm Pract 19: 380-383.

24. Kuroda H, Kawamura M, Hato T, Kamiya K, Kawakubo M, et al. (2008) Syndrome of inappropriate secretion of antidiuretic hormone after chemotherapy with vinorelbine. Cancer Chemother Pharmacol 62: 331-333.

25. Canzler U, Schmidt-Gohrich UK, Bergmann S, Hanseroth K, Gatzweiler A, et al. (2007) Syndrome of inappropriate antidiuretic hormone secretion (SIADH) induced by vinorelbine treatment of metastatic breast cancer. Onkologie 30 : 455-456.

26. Langer-Nitsche C, Luck HJ, Heilmann M (2000) Severe syndrome of inappropriate antidiuretic hormone secretion with docetaxel treatment in metastatic breast cancer. Acta Oncol 39: 1001.

27. Wadd NJ, Tiplady C, Roberts JT (1997) Cisplatin and acute tubular necrosis. Clin Oncol (R Coll Radiol) 9: 267-268.

28. Hamdi T, Latta S, Jallad B, Kheir F, Alhosaini MN, et al. (2010) Cisplatininduced renal salt wasting syndrome. South Med J 103: 793-799.

29. el Weshi A, Thieblemont C, Cottin V, Barbet N, Catimel G (1995) Cisplatininduced hyponatremia and renal sodium wasting. Acta Oncol 34: 264-265

30. Bjornson DC, Stephenson SR (1983) Cisplatin-induced massive renal tubular failure with wastage of serum electrolytes. Clin Pharm 2: 80-83.

31. Liapis K, Apostolidis J, Charitaki E, Panitsas F, Harhalakis N, et al. (2008) Syndrome of inappropriate secretion of antidiuretic hormone associated with imatinib. Ann Pharmacother 42: 1882-1886

32. Kunz JS, Bannerji R (2005) Alemtuzumab-induced syndrome of inappropriate anti-diuretic hormone. Leuk Lymphoma 46: 635-637.

33. Soysal P, Isik AT (2014) Severe hyponatremia due to escitalopram treatment in an elderly adult with Alzheimer's disease. J Am Geriatr Soc 62: 2462-2463.

34. Turner N, Stewart J, Barnett F, White S (2012) Syndrome of inappropriate anti-diuretic hormone secretion secondary to carboplatin after docetaxelcarboplatin-trastuzumab combination for early stage HER-2 positive breast cancer. Asia Pac J Clin Oncol 8: e9-e11.

35. Yokoyama Y, Shigeto T, Futagami M, Mizunuma H (2005) Syndrome of inappropriate secretion of anti-diuretic hormone following carboplatin-paclitaxe administration in a patient with recurrent ovarian cancer. Eur J Gynaecol Oncol 26: $531-532$.

36. Shibata S, Yen Y, Doroshow J, Leong L, Wagman L, et al. (2005) Phase II study of oxaliplatin in patients with unresectable, metastatic or recurrent hepatocellular cancer. J Clin Oncol 22: 14S

37. Berardi R, Caramanti M, Castagnani M, Guglielmi S, Marcucci F, et al. (2015) Hyponatremia is a predictor of hospital length and cost of stay and outcome in cancer patients. Support Care Cancer 23: 3095-3101.

38. Hansen O, Sørensen P, Hansen KH (2010) The occurrence of hyponatremia in SCLC and the influence on prognosis: a retrospective study of 453 patients treated in a single institution in a 10-year period. Lung Cancer 68: 111-114.

39. Hermes A, Waschki B, Reck M (2012) Hyponatremia as prognostic factor in small cell lung cancer--a retrospective single institution analysis. Respir Med 106: 900-904.

40. Tiseo M, Buti S, Boni L, Mattioni R, Ardizzoni A (2014) Prognostic role of hyponatremia in 564 small cell lung cancer patients treated with topotecan. Lung Cancer 86: 91-95. 